\title{
Article \\ Automated Fault Detection and Extraction under Gas Chimneys Using Hybrid Discontinuity Attributes
}

\author{
Qazi Sohail Imran ${ }^{1,2, *(\mathbb{D})}$, Numair A. Siddiqui ${ }^{2}$, Abdul Halim Abdul Latiff ${ }^{1,2} \mathbb{D}$, Yasir Bashir ${ }^{3}{ }^{\circ}$, \\ Muhammad Khan ${ }^{4}$, Kamran Qureshi ${ }^{5}$, Abd Al-Salam Al-Masgari ${ }^{1,2} \mathbb{}$, Nisar Ahmed ${ }^{2}(\mathbb{C}$ \\ and Muhammad Jamil ${ }^{2}{ }^{\mathbb{D}}$
}

check for updates

Citation: Imran, Q.S.; Siddiqui, N.A.; Latiff, A.H.A.; Bashir, Y.; Khan, M.; Qureshi, K.; Al-Masgari, A.A.-S.; Ahmed, N.; Jamil, M. Automated Fault Detection and Extraction under Gas Chimneys Using Hybrid Discontinuity Attributes. Appl. Sci. 2021, 11, 7218. https://doi.org/ 10.3390/app11167218

Academic Editors: Domenico Patella and Paolo Mauriello

Received: 10 May 2021

Accepted: 27 June 2021

Published: 5 August 2021

Publisher's Note: MDPI stays neutra with regard to jurisdictional claims in published maps and institutional affiliations.

Copyright: (c) 2021 by the authors. Licensee MDPI, Basel, Switzerland. This article is an open access article distributed under the terms and conditions of the Creative Commons Attribution (CC BY) license (https:// creativecommons.org/licenses/by/ $4.0 /)$.
1 Centre for Subsurface Imaging, Department of Geosciences, Universiti Teknologi PETRONAS, Seri Iskandar 32610, Malaysia; abdulhalim.alatiff@utp.edu.my (A.H.A.L.); abd_16005741@utp.edu.my (A.A.-S.A.-M.)

2 Department of Geosciences, Universiti Teknologi PETRONAS, Seri Iskandar 32610, Malaysia; numair.siddiqui@utp.edu.my (N.A.S.); nisarpu12@gmail.com (N.A.); jamil287@gmail.com (M.J.)

School of Physics, Universiti Sains Malaysia, USM, Gelugor 11800, Penang, Malaysia; yasir.bashir@usm.my Saudi Aramco, P.O. Box 9060, Dhahran 31311, Saudi Arabia; muhammad.khan.33@aramco.com

Schlumberger, Dhahran 31942, Saudi Arabia; mqureshi6@slb.com

* Correspondence: qazi_17007588@utp.edu.my or xohail@gmail.com

Featured Application: Precise fault detection and extraction have a prime role in understanding the structural framework in the subsurface for multiple reasons, the major ones being oil and gas exploration, development, production, and civil engineering.

Abstract: 3D-seismic data have increasingly shifted seismic interpretation work from a horizonsbased to a volume-based focus over the past decade. The size of the identification and mapping work has therefore become difficult and requires faster and better tools. Faults, for instance, are one of the most significant features of subsurface geology interpreted from seismic data. Detailed fault interpretation is very important in reservoir characterization and modeling. The conventional manual fault picking is a time-consuming and inefficient process. It becomes more challenging and errorprone when dealing with poor quality seismic data under gas chimneys. Several seismic attributes are available for faults and discontinuity detection and are applied with varying degrees of success. We present a hybrid workflow that combines a semblance-based fault likelihood attribute with a conventional ant-tracking attribute. This innovative workflow generates optimized discontinuity volumes for fault detection and automatic extraction. The data optimization and conditioning processes are applied to suppress random and coherent noise first, and then a combination of seismic attributes is generated and co-rendered to enhance the discontinuities. The result is the volume with razor sharp discontinuities which are tracked and extracted automatically. Contrary to several available fault tracking techniques that use local seismic continuity like coherency attributes, our hybrid method is based on directed semblance, which incorporates aspects of Dave Hale's superior fault-oriented semblance algorithm. The methodology is applied on a complex faulted reservoir interval under gas chimneys in a Malaysian basin, yet the results were promising. Despite the poor data quality, the methodology led to detailed discontinuity information with several major and minor faults extracted automatically. This hybrid approach not only improved the fault tracking accuracy but also significantly reduced the fault interpretation time and associated uncertainty. It is equally helpful in detecting any seismic objects like fracture, chimneys, and stratigraphic features.

Keywords: fault detection; automatic fault extraction; hybrid attributes; semblance; structureoriented semblance; fault-oriented semblance; thinned fault likelihood; ant-tracking; discontinuity attributes; gas chimney 


\section{Introduction}

Our Earth is dynamic and tectonic forces reshape it over time. A fault is one of the most notable features in subsurface manifesting these complex forces at work. Sound understanding and interpreting the fault system accurately is crucial to any hydrocarbon exploration and development project's success. With the more frequent availability of 3D-Seismic data, fault interpretation has become more challenging and a tedious job. Moreover, seismic data are often immersed in noise, which makes it difficult to extract useful structural and stratigraphic information. Therefore, traditional fault picking not only becomes challenging but also time-consuming and error-prone. Manual interpretation becomes even more cumbersome when it comes to interpreting smaller discontinuities that are difficult to resolve by seismic data. Automated picking constrained by discontinuity attributes is needed to overcome these challenges. Many researchers have worked on the development of discontinuity or its inverse, seismic continuity attributes, to better visualize and interpret seismic objects. For example, cross-correlation [1], semblance [2], similarity [3], variance [4], and eigenstructure [5,6]. In the available literature, a lot of work has been carried out using individual seismic attributes and filters. If attribute selection is not made carefully, the analysis may yield poor and unsatisfactory results, especially when applied by a novice [7]. A more thoughtful and integrated approach could improve the results significantly. Therefore, our aim is to device a multistep workflow to blend the seismic attributes considered best to capture and optimize the discontinuities, and then use them to extract faults in an automatic manner. The aspects of Dave Hale's novel approach on automated fault detection and extraction have been integrated in our hybrid workflow.

In the context of exploration geophysics, fault dip and strike angles are the main components to illustrate the faults on the outcrop and in the subsurface (Figure 1). Fault throw is a critical parameter that describes the movement of strata that is perpendicular to the strike of a fault. Fault orientation and its throw vary along fault planes in most cases. Fault throw relative to the dip of a fault is usually more significant than displacement along the strike of a fault. Moreover, fault throw vectors are usually more perpendicular to geologic layers, and are therefore easier to estimate than strike-slip displacements, according to [8-10] Dave Hale. However, if there is an insignificant fault throw or minor discontinuities, the traditional fault detection method based on coherency fails to produce satisfactory results.

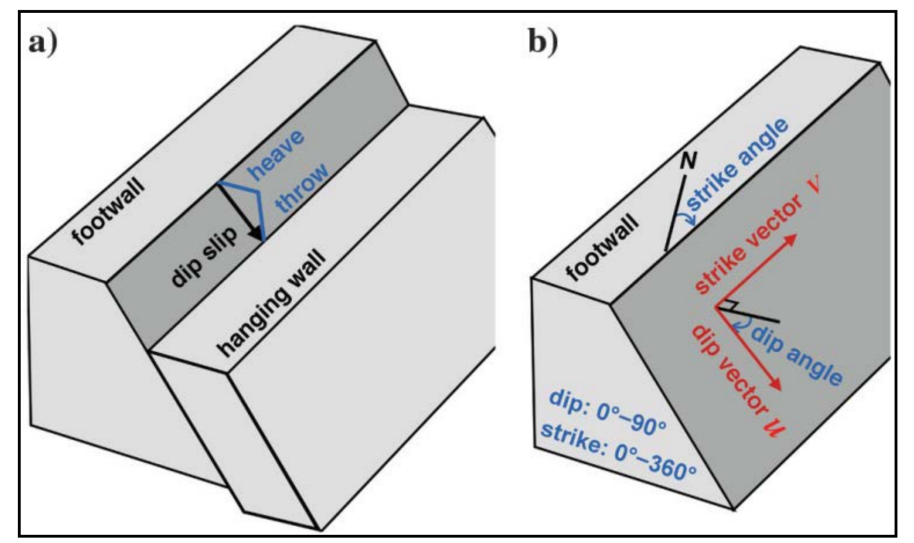

Figure 1. (a) Fault dip represents displacement in the dip direction with respect to a hanging wall whereas fault throw is the vertical component of the slip. Panel (b) shows the fault strike and dip angles with their respective unit vectors [9]. (Reproduced with permission from Xinming Wu, Geophysics, published by SEG, 2016).

To fully address such composite scenarios, we chose to use a hybrid workflow and incorporated multiple discontinuity attributes. Pre-conditioning of the noisy seismic data, being the first step, is the most important and critical step of the workflow. An essential task is to improve reflector continuity, enhance resolution for better imaging and increase 
the signal-to-noise ratio $(\mathrm{S} / \mathrm{N})$ for seismic data interpretation. This step is of particular importance because the seismic data used in this study is moderate to intensely faulted and is marred with gas chimneys [11,12]. The structure is sagging, and reflector's continuity has been heavily compromised due to the chimney effect.

Therefore, an utmost effort has been made to improve the data quality and subdue the noise to make it suitable for seismic interpretation and fault analysis. A structurally oriented adaptive filtering technique was used to address the aforementioned issues, which not only suppressed coherent and random noise but also conserved fine details like edges to extract and map structural and stratigraphic features. To further improve the reflector continuity, a spectral enhancement process was applied on a noise-suppressed seismic cube. This process compensated for low- and high-end missing frequencies and improved the data quality. Next, the optimized volume blended with an ant-tracking attribute was used as input for fault detection using Dave Hale's method. Finally, the resulting tracking volume is used to auto-extract faults with a full user's control on filtering fault surfaces based on multiple criteria such as dip, azimuth and size [13]. Modern technology and advancements in computing power are aiding geoscientists to interpret finer details such as smaller discontinuities that are difficult to resolve using a conventional interpretation methodology. This not also gives flexibility for efficient data reconnaissance but also saves a considerable amount of prospect generation time.

The study area lies in a pull-apart extensional rift basin in offshore Malaysia, called the Malay Basin (Figure 2) [14]. Geologically and seismically, it represents a layer cake model with compressive anticlinal inversion structures. This is one of the deepest (12 KMs at center) basins in SE Asia and is highly petroliferous and has already witnessed an extensive hydrocarbon exploration and production [15-20]. Keeping this context in view, this study has been carried out to device efficient and optimized techniques to understand the structural framework better. The study area is structurally an east-west trending anticline with mostly normal faults at reservoir level [21,22]. A sizeable 3D-seismic cube of around 300 sq. Kms was used for seismic interpretation and fault analysis.

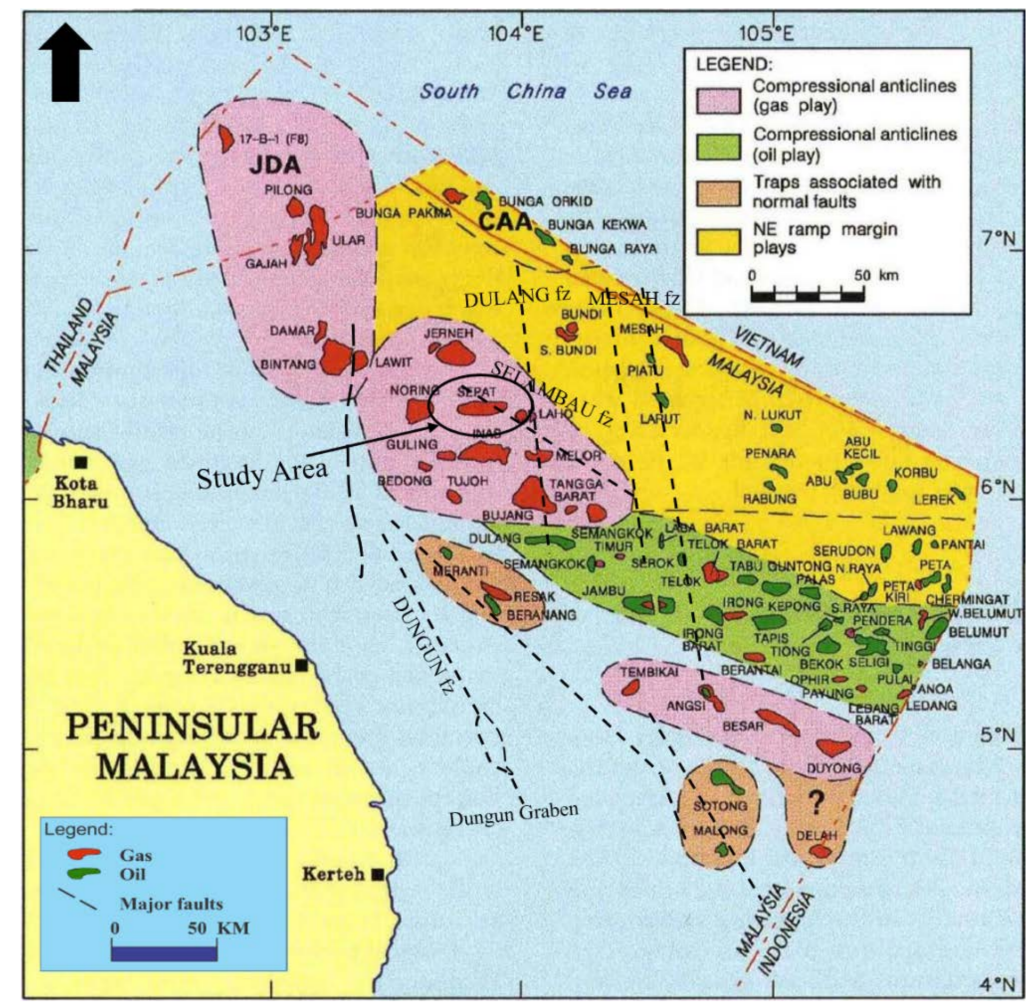

Figure 2. The Malay Basin, showing the study area, play types and major faults zones. (Modified after [23]; faults added based on [24]). 


\section{Methodology}

The heterogenetic nature of the subsurface often does not allow to capture a targeted geological feature such as fault optimally. Seismic discontinuities can be more clearly defined if the detection is based on multiple attributes and suitable filters [25]. Testing and combining several parameters of an attribute and/or using multiple attributes may provide the best results. Different attributes capture different features of the data and then the best ones are recombined in a single, optimized fault volume [7]. The input seismic cube has been subjected to several stages of post-stack processing to enhance the discontinue ties. First, a dip-steering volume was created. A steering volume contains, at every sample position, the dip in the inline- and crossline directions of the seismic events. Several dipsteered filters were then applied to enhance the faults. A dip steering median filter (DSMF) was used to suppress random and coherent noises followed by seismic likelihood (FL) attribute generation to detect and enhance discontinuities. To further fine-tune, thinned fault likelihood (TFL) and ant-tracking attributes were generated with razor sharp faults. The workflow concludes (Figure 3) with the fault extraction using the resultant volume. This automated methodology is based on the aspects of Hale's fault-oriented semblance algorithm in which the attribute highlights fault planes with exceptional clarity. The extracted attributes show a detailed structural framework substantially. The fault system and a large number of subtle lineaments have been characterized in the study area. This hybrid approach is fast and robust. It has increased the confidence in the seismic mapping of the faults and has captured other numerous subtle features which were difficult to identify on the input seismic data.

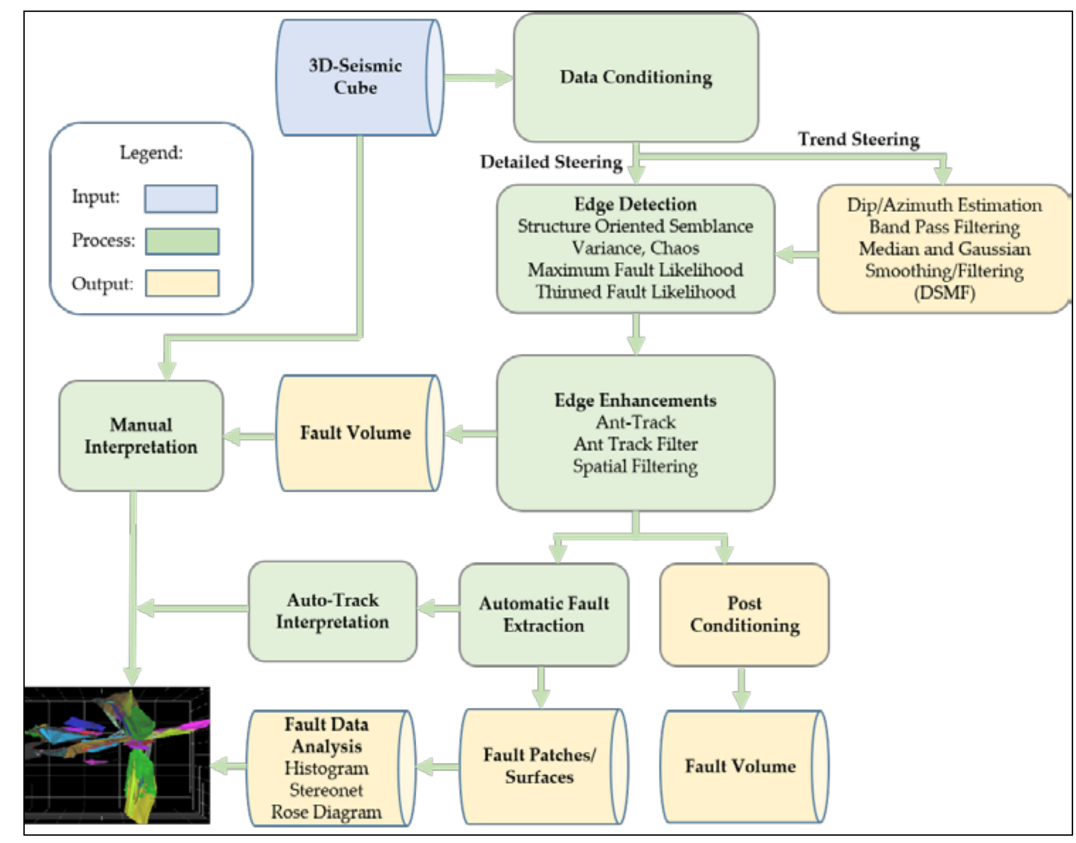

Figure 3. The multistep workflow is comprised of four main steps: 1. Data conditioning; 2. Edge detection and enhancements; 3. Automatic fault extraction; and 4. Fault data analysis.

\section{Results}

\subsection{Seismic Data Conditioning}

Seismic data acquisition and processing may introduce noise in the seismic data. Geometric attributes such as discontinuity or curvature are impacted due to acquisition footprint, coherent noise, and certain processing artifacts [26]. Seismic data conditioning is the key process of removing noise from seismic data and for improving the seismic reflector continuity and fault edges. The seismic conditioning process can improve the clarity of the signal that arises from changes in geology. The main objective of applying the seismic data conditioning process is to achieve a higher signal-to-noise ratio while preserving 
subtle details like faults, even small-scale faults, and amplitude variance due to geological features. Applying a particular attribute with default parameters to unconditioned input data often leads to sub-optimal or even undesired results. The objective is to find a seismic filter that tones down the unrelated discontinuities while leaving the actual ones unaltered. Noise in seismic data cannot be removed in one step necessarily. Major improvements in discontinuity attributes can be achieved in three steps:

1. Conditioning and optimizing the input seismic and dip steering data.

2. Testing and choosing the best parameters for attribute generation.

3. Applying the appropriate filter(s) enhancements on the resultant discontinuity attribute.

There are several post-stack seismic data smoothing filters available to reduce unwanted signals from seismic data and to improve seismic reflector continuity by revealing structural and stratigraphic details. Dip Steer Median Filter (DSMF) is structural oriented filter used in this study that preserves the edges while applying smoothing. Other seismic filters include bandpass filtering, Mean, Median, and Gaussian smoothing, etc. Other worthwhile methods in this regard are based on a Radon transform type filter [27], on singular value decomposition of the seismic data [28,29], or adaptative subtraction algorithms [30].

The standard median filter can subdue the random noise in seismic data but degrades the edges of laterally continuous events such as faults. Therefore, our choice was an edge-preserving dip-steered structure-oriented median filtering to suppress the noise and to improve the signal-to-noise ratio. The dip steer median filter process creates dip and azimuth steering volumes that are needed to orientate the smoothing filters along with the reflectors. The parametrization of DSMF is a very important aspect which needs to be taken care of. The state-of-the-art visualization tools at the interpreter's disposal enable him to test and select the best parameters interactively to condition the seismic data. To create the resultant steering cube using DSMF, the filter size should be decided based on geological complexity and signal-to-noise ratio. This parameter needs to be large enough to take the traces across faults into account while maintaining the structural trends preserving the edges. The resultant volumes capture the dip and azimuth of the dominant reflectors representing real geological trends as shown in Figure 4. Seismic data conditioning retains seismic amplitude variations along with the reflectors by decluttering the seismic data. This improves the reflector's cohesion while enhancing the fault signature. It also helps to remove 'jitter' and acquisition footprints along with the reflectors.

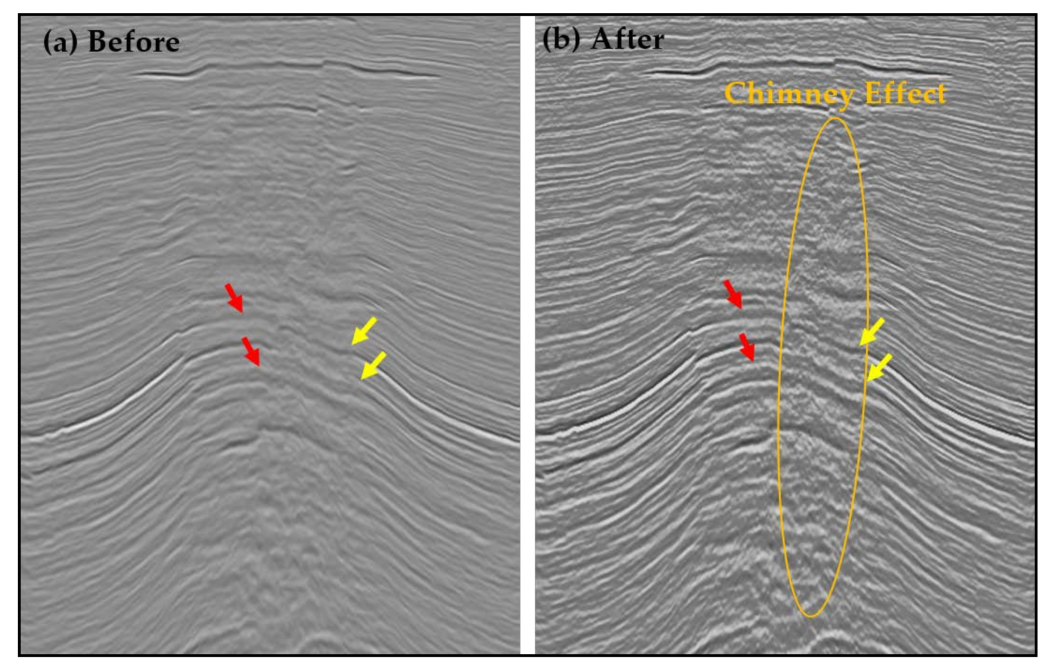

Figure 4. Seismic data conditioning and enhancements applied on input seismic data. (a) Original seismic data before the application of any enhancements. (b) Data enhanced after DSMF/StructureOriented Filtering. The Chimney effect in the vertical ellipse is visible. Red and yellow pointers compare the continuity in horizons and faults respectively. 


\subsection{Edge Detection and Enhancement}

Once seismic data takes the optimal form for discontinuity analysis, an edge detection and enhancement procedure is applied to capture the major and minor faults and discontinuities in the seismic data. Advancements in modern seismic interpretation technologies offer several seismic attributes to compute structural attribute volumes and to enhance faults in seismic data for automatic fault extraction. Some attributes compute the continuity of seismic reflections, such as semblance [2], or coherency [5,31-34], while others measure the discontinuity, such as variance [4,35], or gradient magnitude [36], etc. These attributes are dependent either on amplitude contrast or reflector's continuity and highlight faults only when the set criteria are fulfilled.

For this study, we tested multiple structural-based volume attributes to probe the structural variations across the study area, e.g., variance, curvature, ant-tracking, edge enhancement, edge evidence and chaos. The objective was to compare and choose the best ones to combine. To begin with, the attributes were tested using a few inlines and crosslines with varying parameters. This helped to select the best attribute with suitable parameters. Figure $5 \mathrm{a}-\mathrm{h}$ shows time-slices at $1550 \mathrm{~ms}$ from the attributes tested for this study; (a) shows input seismic data where the faults are hardly visible; and (b) shows the variance attributes, revealing the faults as shown by the red pointers. Variance can map discontinuities and gas chimneys effectively. (c) The curvature attributes may detect subtle structural changes but the results were not helpful for this study. (d) Chaos attributes were not beneficial either, as evident from the figure; it is mainly used to detect faults and fractures. (e) Edge Enhancement attributes were able to detect only major faults; (f) Edge Evidence attributes enhance edge detection by improving continuity. It detected major faults along with unnecessary information from seismic data. (g) A Dip Steering Median Filter (DSMF) preserves the edges for effective detection of discontinuities. The fault traces are slightly visible as shown by the pointers in the figure. (h) Ant-tracking showed comparatively better results and detected several major and minor discontinuities.

As evident from Figure 5, the application of the most traditional discontinuity attributes was not successful in fault delineation in the gas chimney area. Consequently, a few new attributes were integrated and the results were remarkable. These provided the maximum information about the discontinuities and structural variations in the study area. A brief account and the results of the selected attributes are presented below.

\subsubsection{Structure-Oriented Semblance}

We examined several structural attributes, and the results showed varying degrees of success. For example, the Structural Oriented Semblance attribute computes the lateral changes in the seismic response due to structure and stratigraphy variation. It is based on a cross-correlation algorithm and directly applies to the seismic data to create a fault edge preservation cube. It does not need a dedicated dip and azimuth steering volume for orientating itself to the seismic reflector. This attribute calculates the correlation between the neighboring points and identifies the faults and other near-vertical structural features due to low correlation along the neighboring seismic events. It is very sensitive to changes in phase but less susceptible to amplitude changes. Therefore, the areas with high amplitude such as fault edges are not detected with semblance. This is a major drawback of the semblance attribute and it fails to capture discontinuities depending upon seismic amplitude variations in semblance volume. Semblance is not influenced by high dipping seismic reflectors due to the structurally oriented nature of the filter. Semblance depends upon the filter size (lateral extent in-line and crossline direction) and filter depth (vertical extent). Semblance gives us the structure-oriented averaging. However, in order to map the faults properly, fault-oriented averaging should also be known, which is not derived in the traditional semblance attribute. Hence, the standard semblance works well only for vertical or near vertical faults. Therefore, automated fault tracking on such a volume may not produce optimum results until faults have a mostly vertical and consistent throw. 


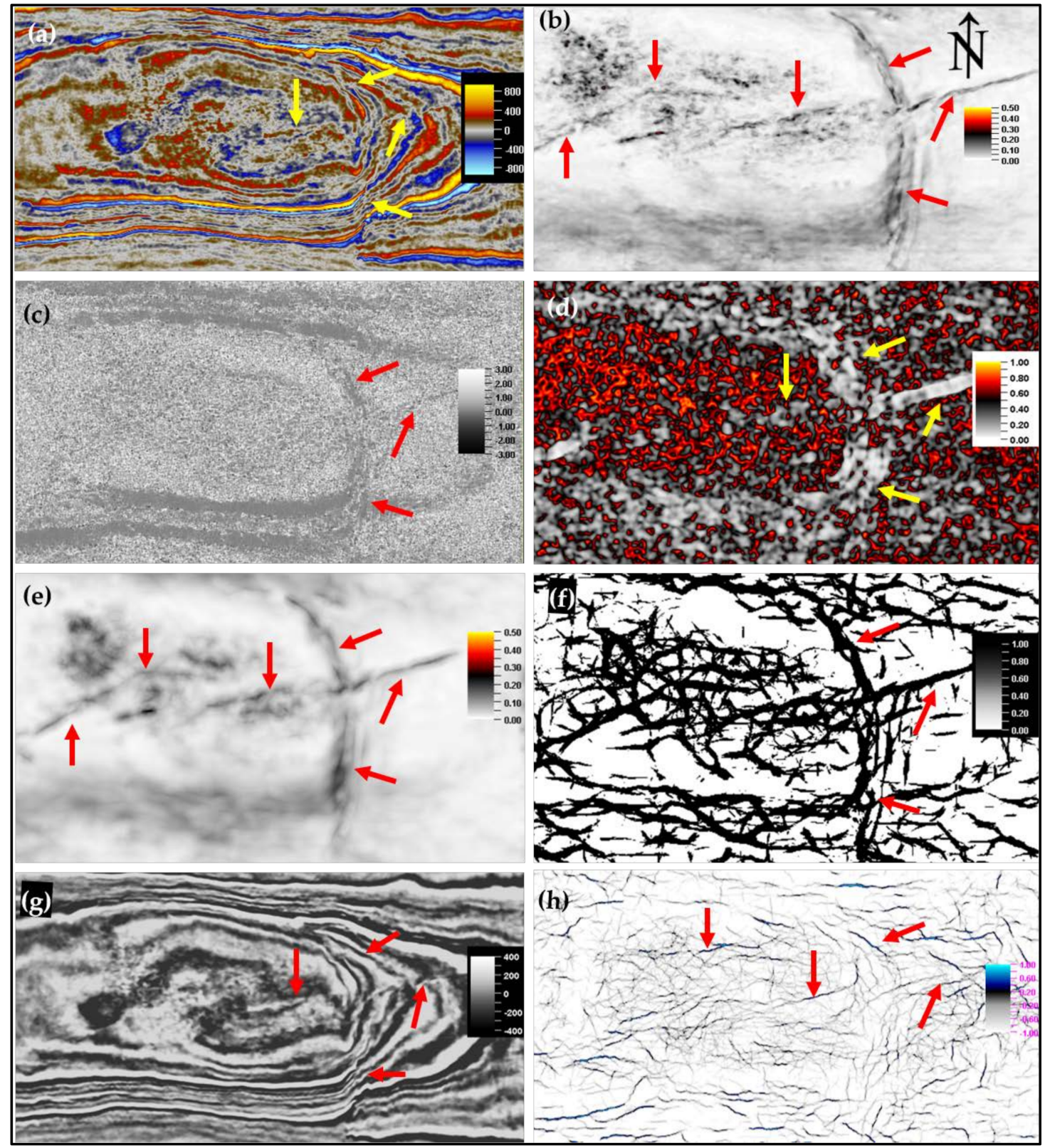

Figure 5. Result of conventional attributes. Time slices at $1550 \mathrm{~ms}$ (a) Difficult to trace faults on input seismic data. (b) Variance attribute reveals the major faults in the study area. Pointers compare the fault presence on all images in this figure. (c) Curvature and (d) Chaos attributes are not helpful. (e) Edge Enhancement attribute is able to detect only major faults, (f) Edge Evidence detects major faults but it is too noisy. (g) Dip Steering Median Filter (DSMF) picks up few fault traces as shown by the pointers. (h) Ant-tracking showed comparatively better results and detected several major and minor discontinuities.

\subsubsection{Dave Hale Fault Image Computation}

Our comparisons show that the best results were achieved by Dave Hale's image calculation fault workflow. The Dave Hale method not only provides the fault probability volume but also the dip and the direction of the fault at each sample. There are two main outputs from this workflow, a fault probability volume and a thinned fault likelihood volume. These detailed aspects make the Dave Hale workflow superior.

\subsubsection{Fault Likelihood (FL) Attribute, the Probability Volume}

Fault likelihood is three-dimensional scanning of structure-oriented semblance volume. Mathematically, fault likelihood is similar to the semblance. However, it not only scans for 
semblance in multiple fault orientations but also measures it at a variety of dips and azimuths to enhance the fault likelihood. The lowest semblance will occur along the fault plane and that will represent the maximum likelihood. The scanning concludes with the images of maximum fault likelihood and its corresponding fault strikes and dips [37]. Fault likelihood attributes represent the probability of faults at each sample location. Figure 6 a shows the Fault Likelihood (FL) image.

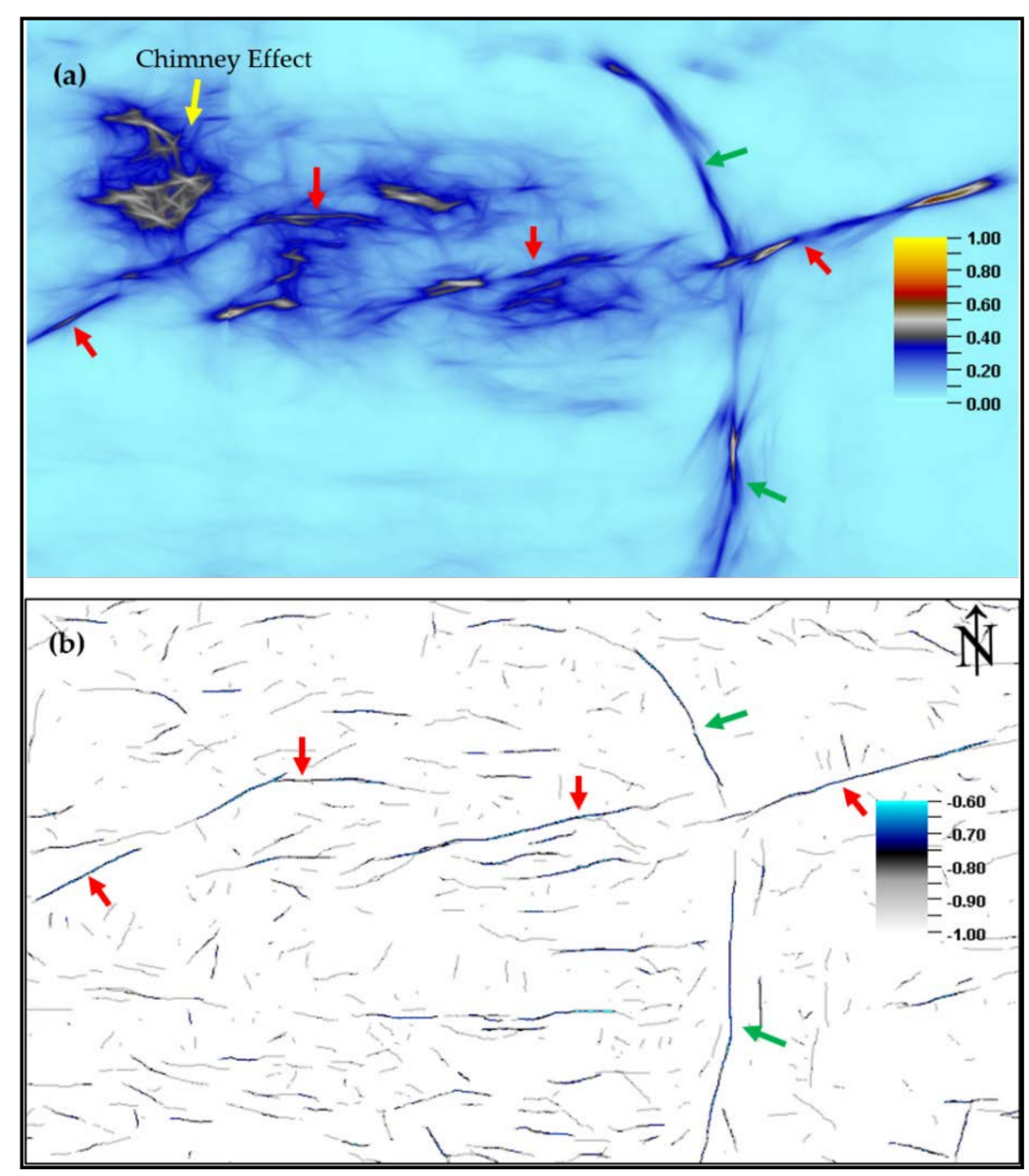

Figure 6. Time slices at $1550 \mathrm{~ms}$. (a) Fault likelihood (FL) or the fault probability volume, which has been computed using fault-oriented semblance (b) Thinned Fault Likelihood (TFL) image showing razor sharp discontinuities across the study area. Red and green pointers in both images indicate major faults.

With estimates of reflective paths, structure-based semblance could be defined as:

$$
\text { Semblance }=\frac{(\text { Image })_{s}^{2}}{\left(\text { Image }^{2}\right)_{s}}
$$

Which shows the semblance value, $(.)_{s}$, as structure-oriented. Similarly, computed ratios vary greatly where the numerators and denominators are small [38]. This is because usually, before computing emulsion ratios, we perform a supplementary smoothing of numerators and denominators. Therefore, the equation after applying the modifications is as under:

$$
\text { Sembalance }=\frac{\left((\text { image })_{s}^{2}\right)_{f}}{\left(\left(\text { image }^{2}\right)_{s}\right)_{f}}
$$


Therefore, the $\mathrm{f}$ is the additional smoothing to the images, which follows the faults. Finally, the vertical smoothing to the data is accounted for, to a vertical extent, the low semblance appearance:

$$
f=1-\text { Semblance } 8
$$

\subsubsection{Thinned Fault Likelihood (TFL) Attribute}

Fault likelihood attribute is further fine-tuned to get razor sharp images of structural discontinues called thinned likelihood seismic attribute. The thinned likelihood attribute enhanced the major and minor discontinuities that can be further used for automatic fault extraction workflow. Figure $6 \mathrm{~b}$ shows Fault Likelihood (FL) image. Thin likelihood volume is merged with dip and azimuth and ant-tracking volume to produce fault-tracking volume, which is the main input for the automated fault extraction process.

\subsection{Automatic Fault Extraction}

To build an accurate geological model, it is of prime importance to understand the structural framework of the subsurface. Traditionally, this has been accomplished by manually picking the faults identified on the seismic dataset, which is an inefficient and time-consuming process. It is even more so with poor quality seismic data. In most cases, fault interpretation is also influenced by the predefined bias of the interpreter. By utilizing the modern tools and techniques, Geoscientists today can interpret virtually all seismic discontinuities in a seismic volume that are difficult to pick otherwise. Automated fault extraction enables the seismic interpreter to generate an initial fault network from 3D seismic data with very little manual intervention. The interpreted faults can be edited later in a much shorter time in an efficient manner. Consequently, this renders much-needed time to the interpreter for other prospect generation activities.

Efforts in automatic fault detection and extraction has accelerated during the last two decades. Several seismic attributes have been developed, such as coherency, variance and chaos, which have been used to capture the fault locations, but with limited success due to seismic signal heterogeneities in the vicinity of the faults affecting the attribute values [39]. More recently, machine learning techniques have grabbed considerable attention in this direction, but these require a lot of data to train the software. Huge datasets are not readily available to everyone; hence machine learning techniques may not produce viable results in the foreseeable future.

Keeping this context in view, methods based on structure-oriented semblance [40] have been more successful and produced the best results to date. Fault Likelihood is one of these methods which was developed by Dave Hale in 2013. Most of the available methods are based either on seismic continuity or discontinuity; however, Dave Hale's methodology is based on fault-oriented semblance attributes, which makes it superior. The method supports manual, semi-automated based on seed faults and fully automated fault interpretation. The tracking algorithm is designed to calculate the fault dips and strikes constrained by predefined ranges to maximize the fault likelihood across the seismic volume. The input parameters are crucial to the procedure and depend on how seismic reflectors are dipping. If the geological scenario is simply layer-cake-like, small-angle ranges and fewer scan iterations may provide good results. Wider dip and strike ranges are recommended if detailed information is intended. Here, we have used the angle $\theta$ to scan the fault likelihood frequencies (f):

$$
\begin{gathered}
\text { Fault dip angle }=\theta \\
\text { Highly Dipping fault } 90^{\circ} \text { or Verti cal fault }=\theta=0
\end{gathered}
$$

After the suitable parameter selection was made, an automatic fault extraction algorithm was run on fault-tracking volume (TFL+Ant-tracking combined) to generate fault patches. More than 500 major and minor fault patches were extracted from the fault-tracking volume, as shown in Figure 7a. 


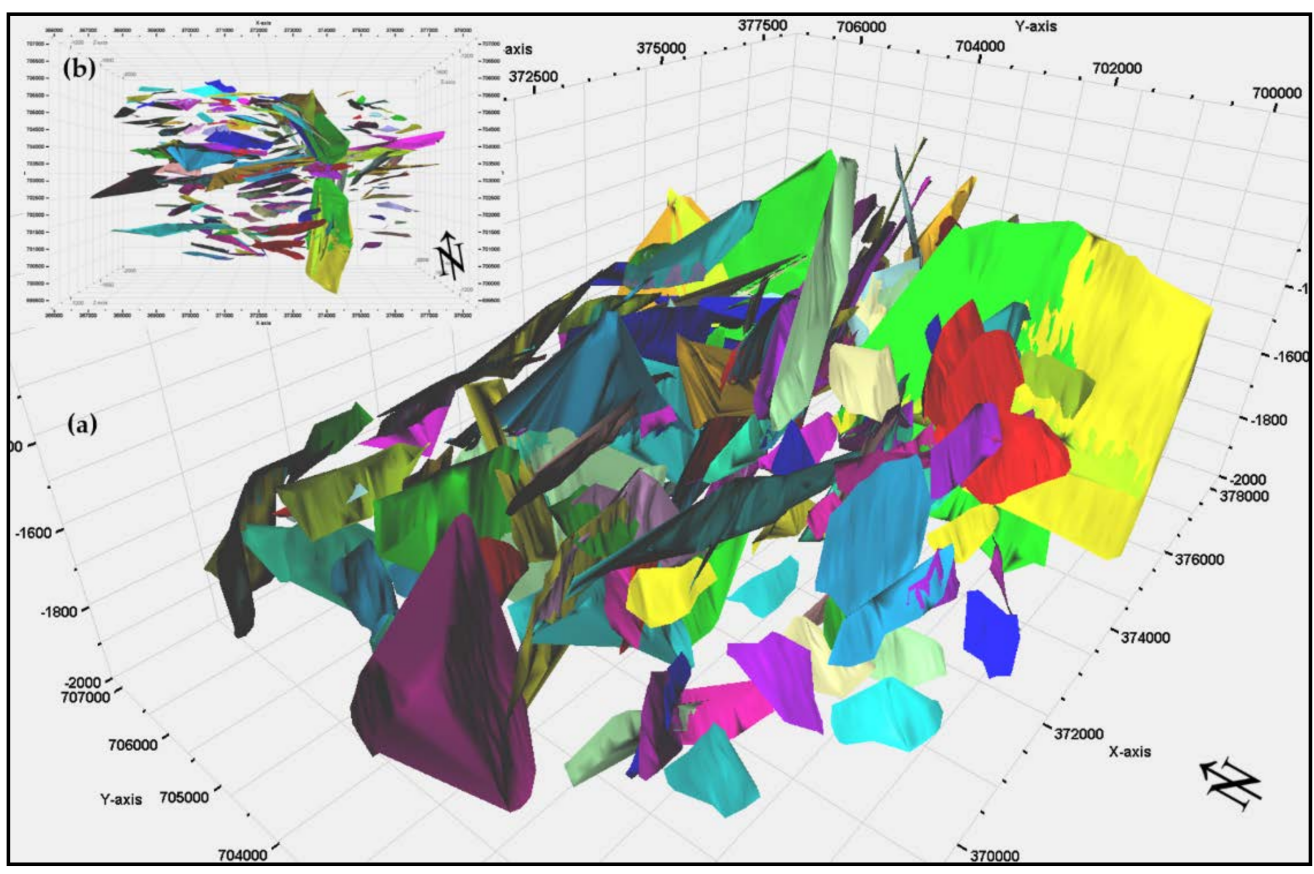

Figure 7. (a) 3D view of all major and minor fault patches extracted automatically using the faulttracking volume. The inset $(\mathbf{b})$ shows a planner view of fault patches.

\section{Ant-Tracking Computation}

Ant-tracking is a superior algorithm that adds further value to the workflow. It boosts not only major and minor discontinuities but also offers automated fault extraction and useful fault analysis tools. The algorithm uses the principles from ant colony systems to extract surfaces appearing like trends in very noisy data.

Intelligent software agents called ants try to extract features from the data whose behavior corresponds to a fault. If many ants pick up a certain behavior or trend, it is extracted. Whereas noise and the remains of reflectors should be extracted by no ants or by only a single ant, in which case they will be deleted. The approach is fully $3 \mathrm{D}$ and can take full advantage of surface information in the neighboring voxels. This makes it possible to derive detailed information from the data or an attribute. By writing the extracted surfaces back to a volume, we get what is referred to as an enhanced attribute, or an ant track cube. This cube contains only what is likely to be true fault information. Ant-tracking can extract faults from a pre-processed seismic volume or an attribute like a fault likelihood. An ant-tracking algorithm combined with a thinned fault likelihood attribute was used to extract numerous fault patches automatically. The patches can then be picked automatically or manually to merge into elementary fault planes. Since fault likelihood is a very sensitive process, it picks up all discontinuities regardless of their size. To get a clear picture and organization of the desired faults, we used different approaches. In the first one, fault directions were used as a constraint and azimuthal filters were applied during ant-tracking attribute generation. Azimuthal filters applied in east-west and north-south directions helped to identify the orientation of the faults. Figure 8 shows the ant-tracking volumes where Figure 8a shows east-west trending faults and Figure 8b depicts faults with a northsouth trend. Faults based on their orientation were effectively separated and analyzed this way. The results show that most of the faults are east-west trending in the study area. 


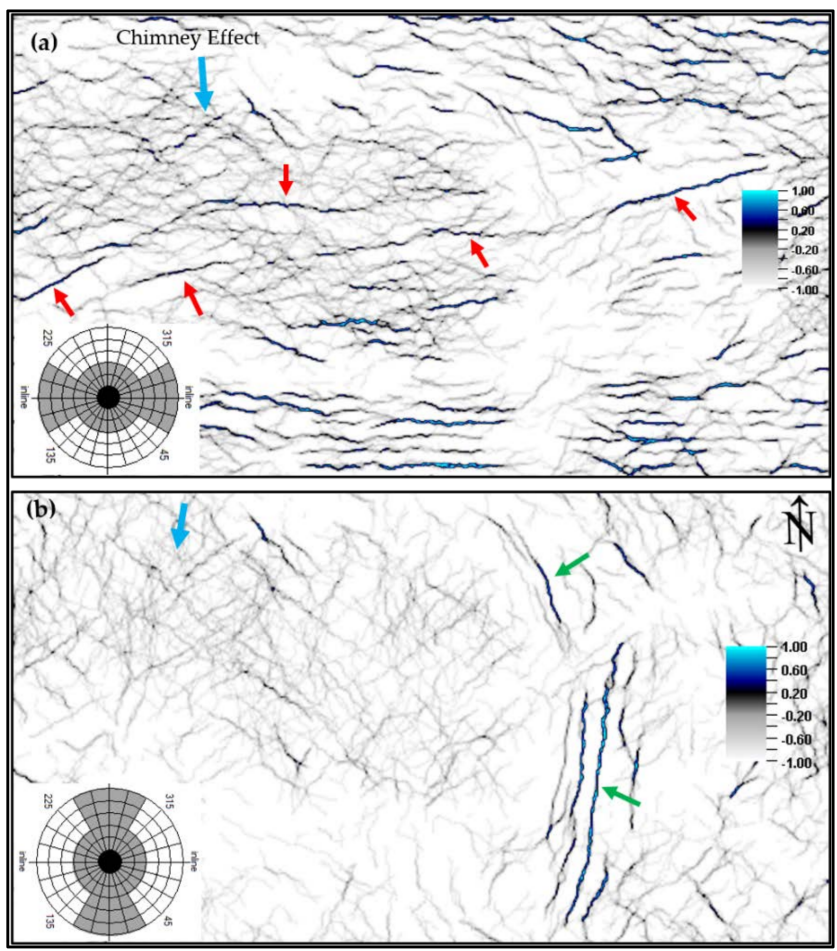

Figure 8. Time slice at $1550 \mathrm{~ms}$ from ant-tracking attribute volume (a) showing only east-west trending faults controlled by azimuthal filtering available in stereonet. (b) Only north-south trending faults were controlled by stereonet. Red and green pointers show the major faults.

Another useful technique is to co-render the seismic amplitude with the generated attributes. Figure 9 shows co-rendering of seismic amplitudes (greyscale), fault likelihood attributes (bright color) and thinned fault likelihood attributes (yellow intensity). The terminations line up to make a trend along the fault likelihood helping the interpreter to identify the fault surfaces.

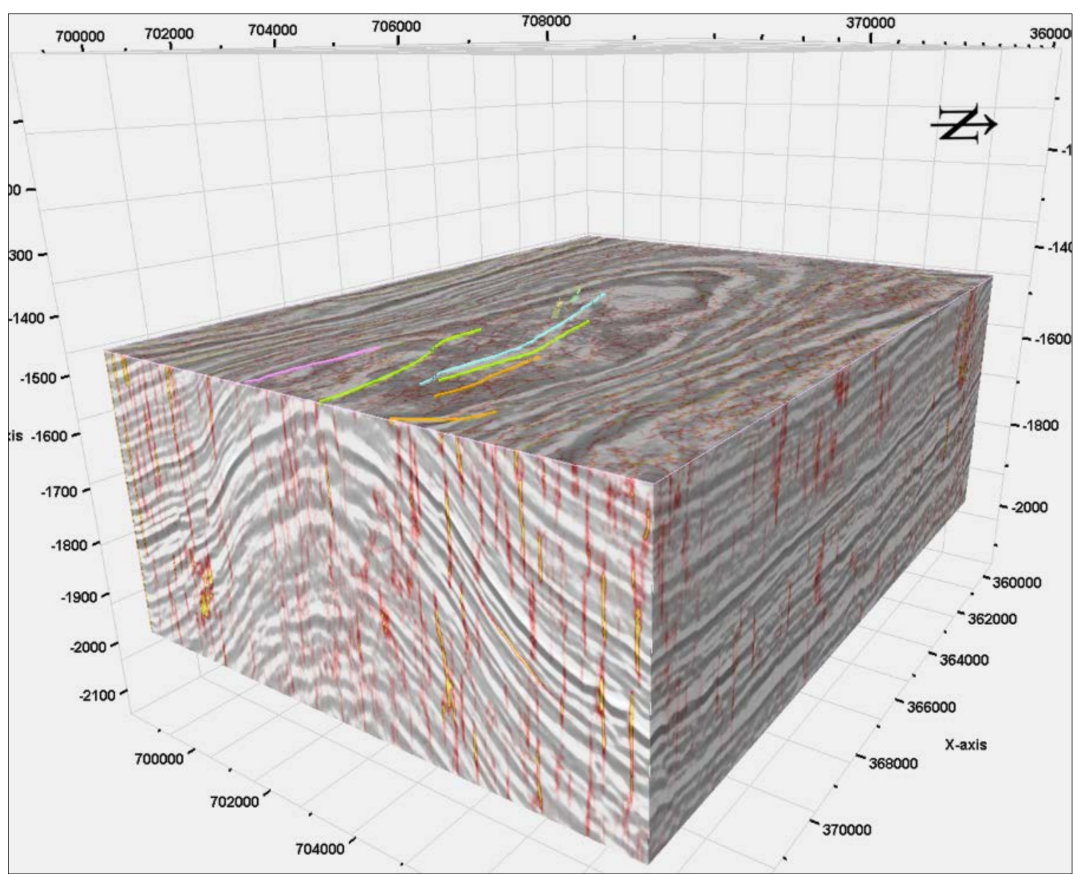

Figure 9. 3D view of co-rendering of seismic amplitude (greyscale), fault likelihood attribute (bright color), and thinned fault likelihood attribute (yellow intensity). 
The third approach to analyze the resultant discontinuities is to perform multiple iterations to generate a volume that eliminates minor discontinuities but keeps the major ones. Figure 10a shows thinned fault likelihood with all possible major and minor discontinuities, whereas Figure 10b shows the second iteration of the thinned fault likelihood with minor discontinuities removed, presenting a much cleaner result.

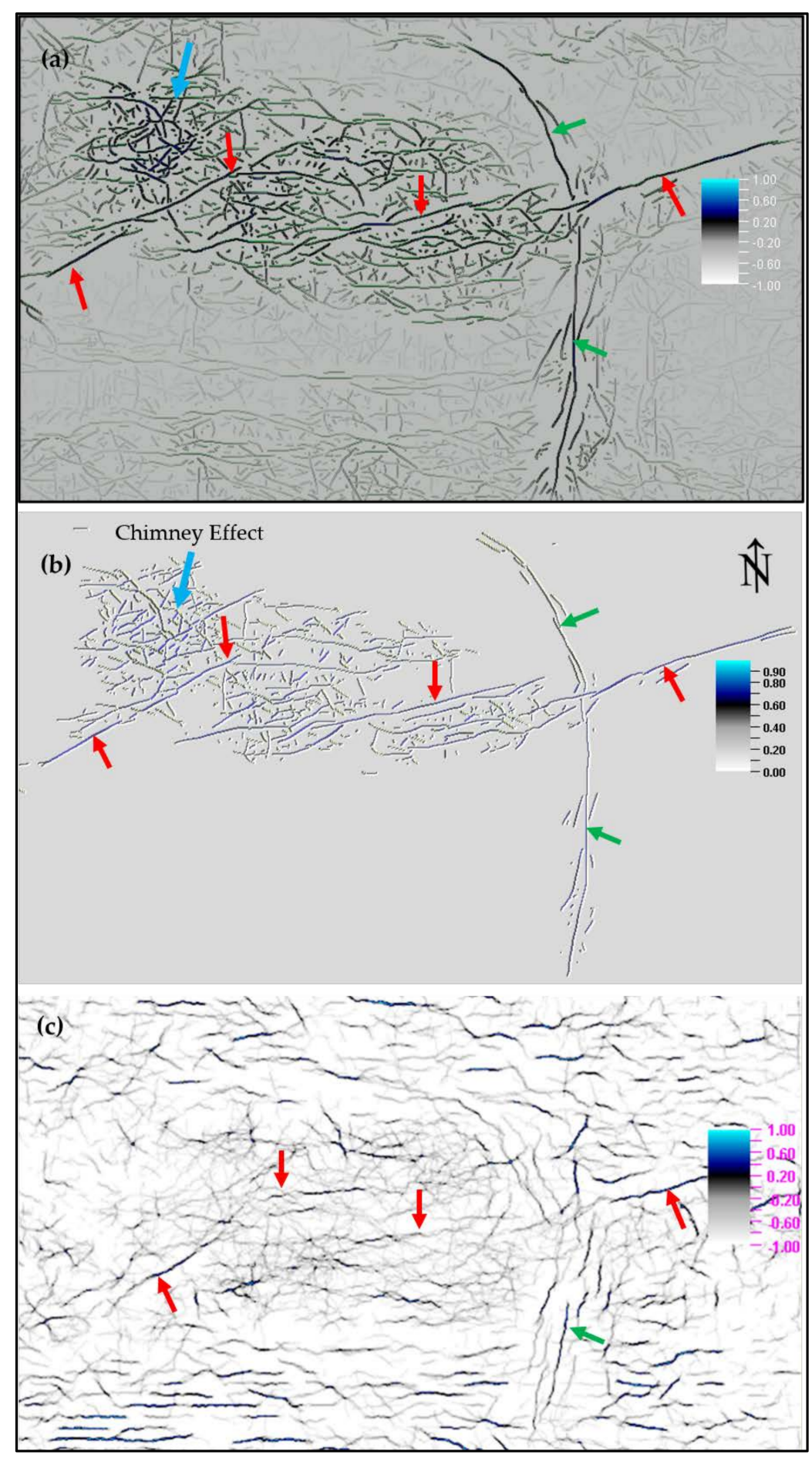

Figure 10. (a) Thinned fault likelihood combined with ant-tracking attribute is showing all major and minor discontinuities. (b) Unwanted and minor discontinuities have been removed through an iterative process, presenting a much cleaner result; (c) shows ant-tracking of variance cube and compares the results of hybrid attributes (in $\mathbf{a}, \mathbf{b}$ ) used in this study to a standard edge detection attribute like variance. Red and green pointers mark the major faults on all images. 
Figure 10c shows the ant-tracking of variance cube. Figure 10a-c also provides an opportunity to compare the results of hybrid attributes used in this study and a standard edge detection attribute variance. It is evident that the chosen attributes have delineated razor-sharp discontinuities successfully.

\subsection{Fault Data Analysis using a Rose Diagram, Histogram, and Stereonet}

Once the fault surfaces are automatically generated, the immediate challenge is to reduce and simplify the structural framework by sorting, organizing and merging. To control the discontinuities, a filtering option is available with fault data analysis. Stereonet, Histogram, and Rose diagrams (dip and strike) (Figure 11) are very useful tools that offer a lot of customizable options to keep or eliminate discontinuities with full user control. These are interactive and provide control over discontinuities based on dip, azimuth, surface area, and confidence. For instance, the Rose diagrams (Figure 11a,b) record and show the number of samples which have a thinned fault likelihood value above a predefined threshold. The diagrams are divided into several sectors representing strike and/or dip angles/directions. The color, radius, and length of each sector signify the information like the number of samples, dip angle range, and sample count. The results of the extracted faults were displayed on the Stereonet (Figure 11c), which showed more than 500 fault patches scattered in different orientations. Based on various available filtering criteria like dip, azimuth, and surface area, the results showed that most patches were clustered in the north-south direction with a dip ranging from 60 to 90 degrees. The histogram shows (Figure 11d) that the surface area of the selected patches ranges from $8000-30,000 \mathrm{~m}^{2}$. Figure 12a shows the application of these tools where the filter based on fault size and dip direction has eliminated all minor discontinuities, whereas major fault surfaces have been retained. Additionally, fault surfaces can also be picked/deleted and merged manually.

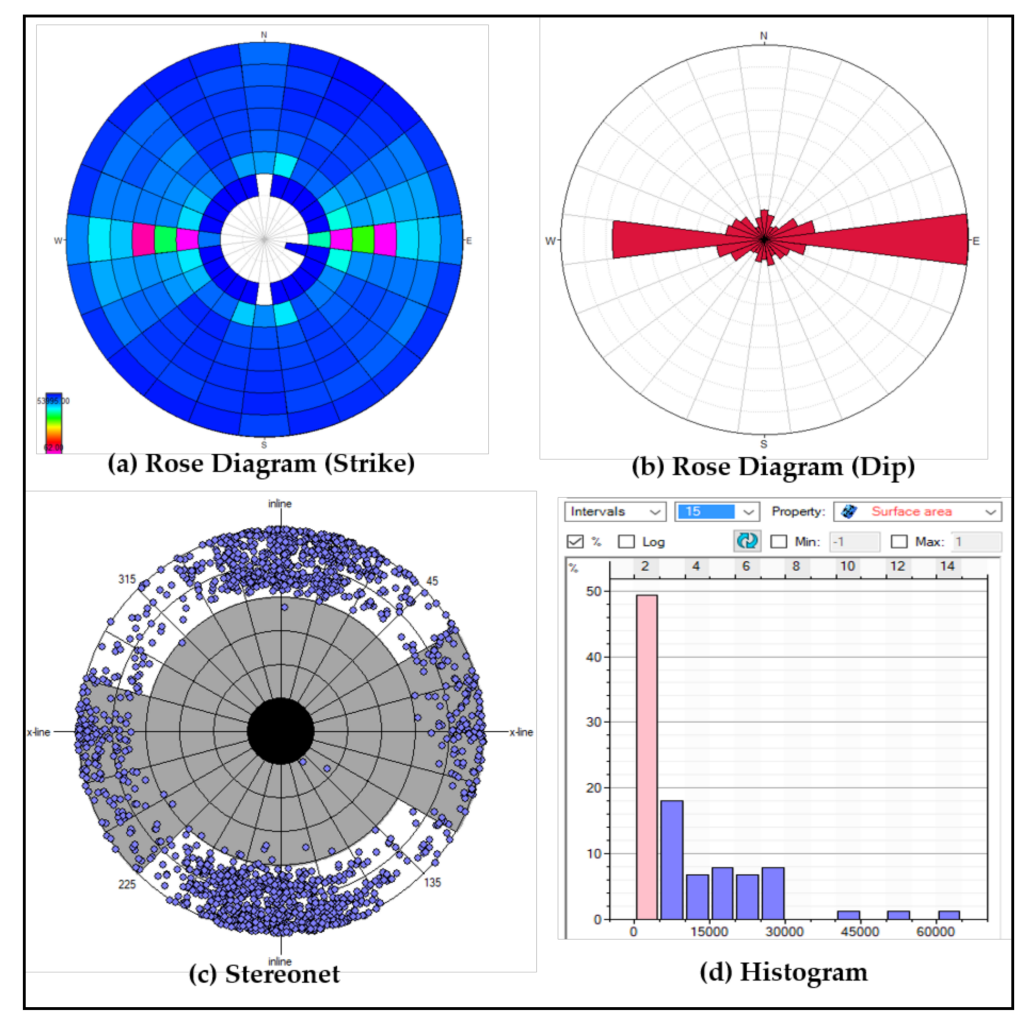

Figure 11. Fault data analysis tools. (a) Rose diagram (strike) and (b) Rose diagram (dip) provide information about dip/strike angle and direction of fault patches based on sector division. (c) Stereonet shows orientation, dip, and the azimuth of the patches interactively. (d) Histogram offers the filter options like dip, azimuth, surface, and size of the patches. It can also be used interactively to filter the discontinuities based on the mentioned criteria. 


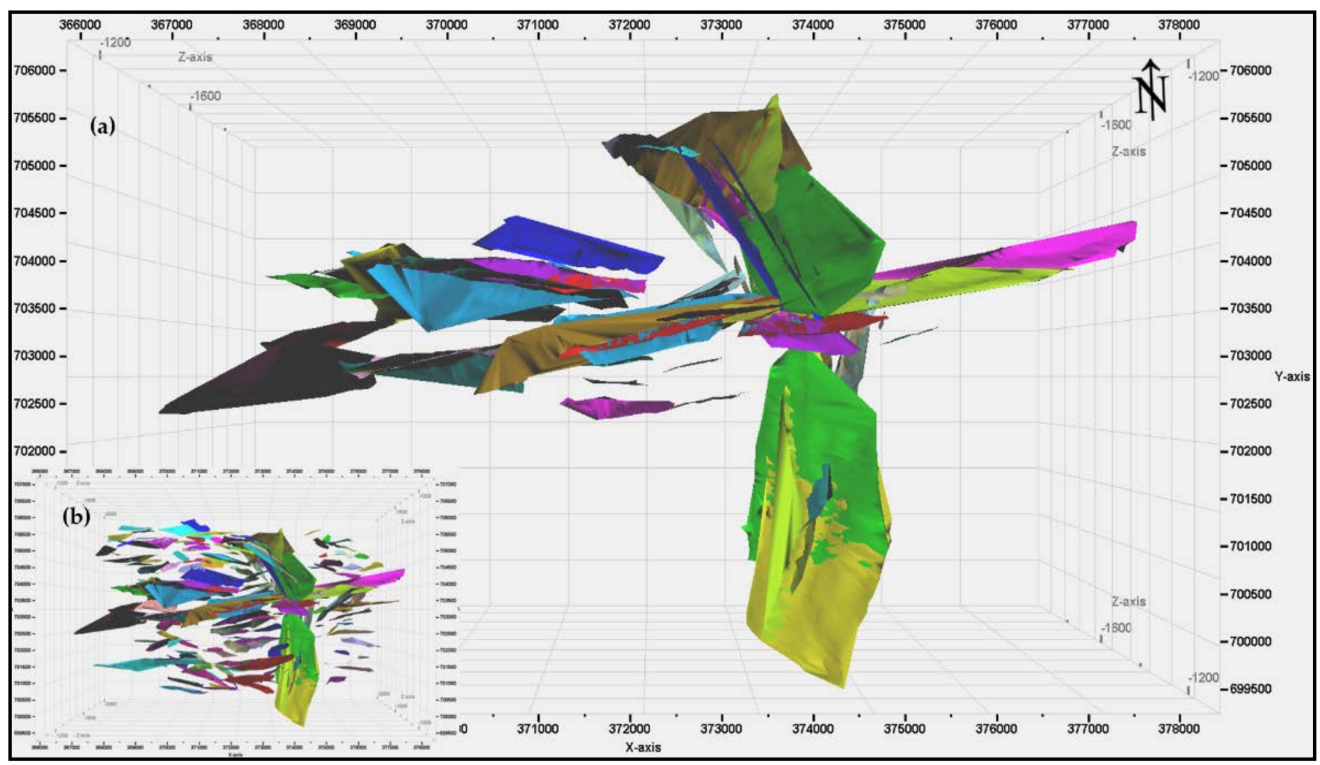

Figure 12. (a) 3D view of filtered major fault surfaces using fault data analysis tools. Inset (b) shows all major and minor discontinuities in the planner view.

\section{Discussion}

The fault interpretation is vital in understanding the subsurface structural framework [41]. A multistep hybrid workflow was devised to avoid falling into the classic pitfall of cumbersome computation. The objective was to make the fault interpretation efficient and automatic. Dave Hale's innovative fault likelihood coupled with conventional attributes were used to detect and auto-extract the faults. The method can be regarded as 3D semblance as it measures semblance at a variety of dips and azimuth. This novel approach has been successfully applied on a faulted reservoir under a gas chimney in offshore, Malaysia. It is comprised of four main steps: (1) seismic data conditioning using dip steered median filter (DSMF); (2) fault detection and enhancement by generating fault likelihood and combining it with conventional attributes; (3) automated fault extraction; and (4) fault data analysis. The application of the steering cube as well as the structural oriented filtering significantly enhanced and sharpened the discontinuity features. The effective integration of discontinuity attributes enabled the automatic fault extraction, which helped to build a structural framework for mapping fault relationships with juxtaposed strata. This paper also discussed several tools and techniques available for fault data analysis that can quickly filter, sort, organize, and merge the fault surfaces. These include the iteration process to clean up and refine the resulting volume by eliminating any unwanted discontinuities. Another approach is to use statistical graphs to filter the faults based on dip, azimuth, surface area, and confidence of the faults to be tracked. By applying this automatic workflow, more than 500 fault surfaces were generated in a few hours. The fault surfaces were filtered and chosen for further analysis based on several criteria using the fault analysis tools. Major surfaces were merged to make fault planes and were then converted into the fault interpretation. Subsequently, the fault interpretation was sent to the fault model to form a fault framework, as shown in Figure 13. This framework can now be incorporated into static modeling to understand the subsurface structural framework. To conclude, this study provided an advanced workflow that identified and auto extracted the faults with unprecedented clarity. It is fast and completed in a fraction of time compared to what would have been required for traditional manual picking. As future work, the methodology can be tested to explore fracture corridors and stratigraphic features to gauge its adequacy and effectiveness. It is customizable and can use other attributes and algorithms to further improve it. 


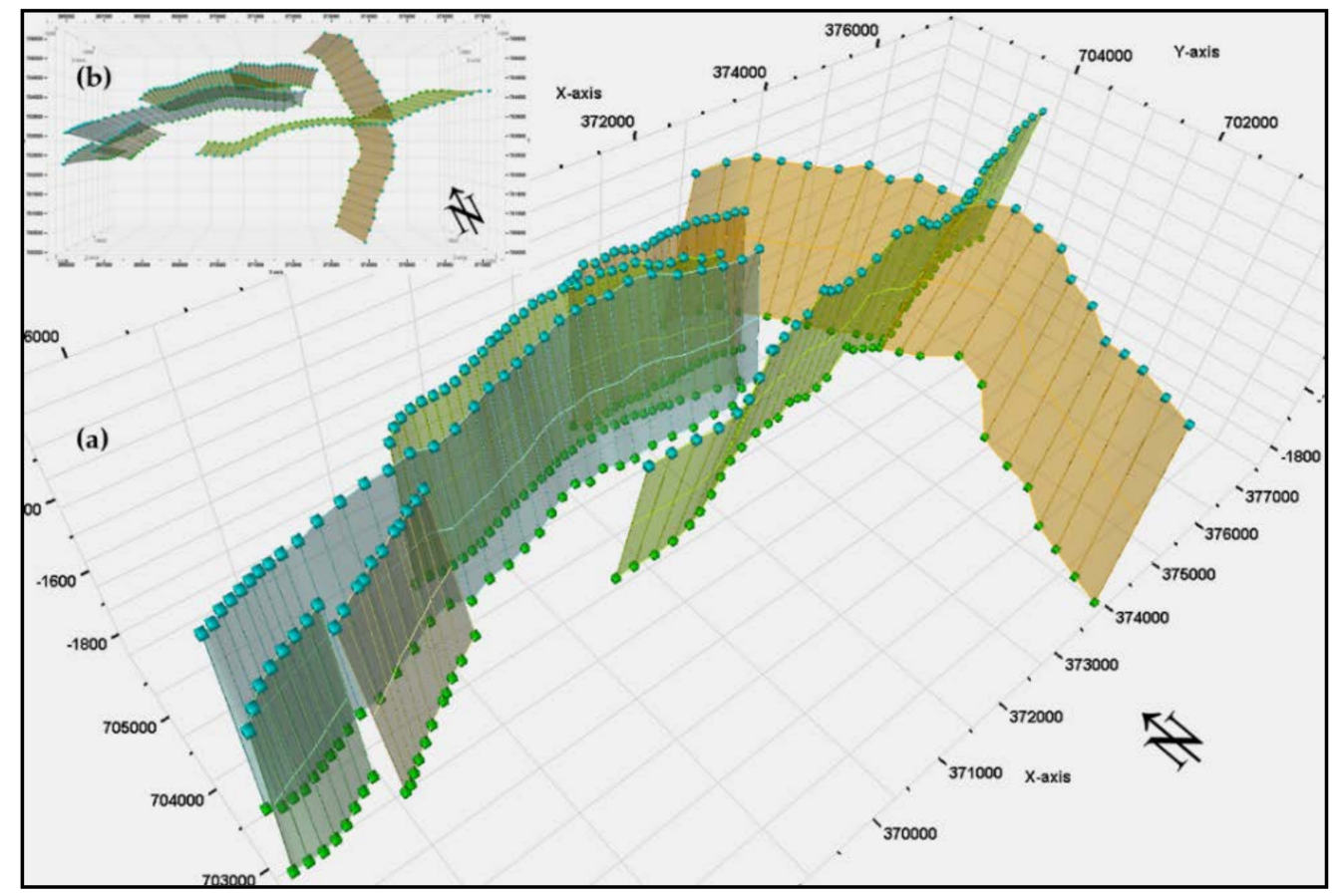

Figure 13. (a) The fault framework, also called fault model in the 3D view, which is the outcome of this research work. The inset (b) shows the framework in the planner view. The fault model is ready to be incorporated into static modeling.

\section{Conclusions}

This research work proposes a superior workflow to automate the fault detection and extraction process. It is built on 3D fault-oriented semblance, and hence can identify the discontinuities even where the traces are locally continuous across the faults. Its application on a faulted reservoir successfully identified and extracted the numerous faults. The results are promising and can play a pivotal role in prospect generation by providing detailed structural and stratigraphic mapping. Equipped with the dip and azimuth arguments, accuracy and efficiency in characterizing and developing mature reservoirs have also been significantly enhanced through this innovative workflow technology. It is fast and robust and is expected to reduce the fault interpretation efforts and time significantly, potentially from days to hours. This ensures that the interpreter utilizes more time on other exploration activities. Some limitations and caution should be kept in mind while executing the workflow: (1) The quality of the results depends upon the true understanding of each step of the workflow in the context of the final objective. This enables the interpreter to identify the problems, find solutions and apply them in a suitable manner. (2) The workflow is computationally intensive and may take a longer time on large volumes. The execution time can be reduced significantly if the computation is distributed over multi-node clusters called GPU-enabled processing.

Author Contributions: Conceptualization, Q.S.I., and M.K.; methodology, Q.S.I., and M.K.; software, Q.S.I., and M.K.; validation, N.A.S., M.K., Y.B., K.Q., and A.A.-S.A.-M.; formal analysis, Q.S.I., Y.B., N.A. and M.J.; investigation, Q.S.I., M.K., and A.A.-S.A.-M.; resources, A.H.A.L.; data curation, A.H.A.L.; writing—original draft preparation, Q.S.I.; writing—review and editing, Q.S.I., N.A.S., Y.B., and M.K.; visualization, Q.S.I., M.K., and K.Q.; supervision, N.A.S., A.H.A.L., Y.B., M.K., and K.Q.; project administration, A.H.A.L.; funding acquisition, N.A.S., and A.H.A.L. All authors have read and agreed to the published version of the manuscript.

Funding: This research was funded and supported through the following projects/grants: Identifying and evaluating the low resistivity reservoir in Malay Basin (YUTP) with cost center (015LC01-161), Integrated Elastic Properties Prediction via Deep Learning with cost center (015MD0-059), Artificial 
intelligence on seismic attributes with cost center (015MD0-057), YUTP with cost center (015LCO-220) and Petroleum Research Fund (PRF) (Grant No.0153AB-A33).

Institutional Review Board Statement: Not applicable.

Informed Consent Statement: Not applicable.

Data Availability Statement: The data used in this study are confidential and cannot be released.

Acknowledgments: The authors are grateful to Universiti Teknologi Petronas, Centre for Subsurface Imaging (CSI), and PETRONAS, Malaysia, for providing the required data and funding for this research work. We would like to acknowledge Schlumberger and the dGB Earth Sciences for donating the academic licenses of Petrel and OpendTect to the Center for Subsurface Seismic Imaging (CSI), Universiti Teknologi PETRONAS, Malaysia. We would like to thank the Geoscience Department, Universiti Teknologi PETRONAS, and all colleagues for their support and constructive input. We also wish to thank the anonymous reviewers whose valuable input improved this work.

Conflicts of Interest: The authors declare no conflict of interest.

\section{References}

1. Bahorich, M.; Farmer, S. 3-D seismic discontinuity for faults and stratigraphic features: The coherence cube. Lead. Edge 1995, 14, 1053-1058. [CrossRef]

2. Marfurt, K.J.; Kirlin, R.L.; Farmer, S.L.; Bahorich, M.S. 3-D seismic attributes using a semblance-based coherency algorithm. Geophysics 1998, 63, 1150-1165. [CrossRef]

3. Tingdahl, K.M.; De Groot, P.; Heggland, R.; Ligtenberg, H. Semi-automated object detection in 3D seismic data. In Proceedings of the 2001 SEG Annual Meeting, San Antonio, TX, USA, 9-14 September 2001.

4. Van Bemmel, P.; Pepper, R. Seismic Signal Processing Method and Apparatus for Generating a Cube of Variance Values. U.S. Patent US6151555 A, 21 November 2000.

5. Marfurt, K.J.; Sudhaker, V.; Gersztenkorn, A.; Crawford, K.D.; Nissen, S.E. Coherency calculations in the presence of structural dip. Geophysics 1999, 64, 104-111. [CrossRef]

6. Gersztenkorn, A.; Marfurt, K.J. Eigenstructure-based coherence computations as an aid to 3-D structural and stratigraphic mapping. Geophysics 1999, 64, 1468-1479. [CrossRef]

7. Brouwer, F.; Huck, A.; Marfurt, K.J.; Gao, D.; Barnes, A.; Chopra, S.; Corrao, A.; Hart, B.; James, H.; Pacht, J.; et al. An Integrated Workflow to Optimize Discontinuity Attributes for the Imaging of Faults. In Attributes: New Views on Seismic Imaging-Their Use in Exploration and Production; SEPM Society for Sedimentary Geology: Tulsa, OK, USA, 2011.

8. Hale, D. Methods to compute fault images, extract fault surfaces, and estimate fault throws from 3D seismic images. Geophysics 2013, 78, O33-O43. [CrossRef]

9. Wu, X.; Hale, D. 3D seismic image processing for faults. Geophysics 2016, 81, IM1-IM11. [CrossRef]

10. Cohen, I.; Coult, N.; Vassiliou, A.A. Detection and extraction of fault surfaces in 3D seismic data. Geophysics 2006, 71, P21-P27. [CrossRef]

11. Abdul Latiff, A.H. Shallow gas cloud illumination analysis by the focal beam method. J. Geophys. Eng. 2016, 13, 96-108. [CrossRef]

12. Bashir, Y.; Babasafari, A.A.; Alashloo, S.Y.M.; Muztaza, N.M.; Ali, S.H.; Imran, Q.S. Seismic Wave Propagation Characteristics Using Conventional And Advance Modelling Algorithm For D-Data Imaging. J. Seism. Explor. 2021, 30, 21-44.

13. Al-Maskeen, A.A.; Ali, S.S.; Khan, M. The Impact of Automated Fault Detection and Extraction Technology on Seismic Interpretation. In Proceedings of the SPE Middle East Oil and Gas Show and Conference, Manama, Bahrain, 18-21 March 2019.

14. Ghosh, D.; Halim, M.F.A.; Brewer, M.; Viratno, B.; Darman, N. Geophysical issues and challenges in Malay and adjacent basins from an E \& P perspective. Lead. Edge 2010, 29, 436-449.

15. Ghosh, D.; Sajid, M.; Ibrahim, N.A.; Viratno, B. Seismic attributes add a new dimension to prospect evaluation and geomorphology offshore Malaysia. Lead. Edge 2014, 33, 536-545. [CrossRef]

16. Almasgari, A.A.; Elsaadany, M.; Latiff, A.H.A.; Hermana, M.; Abd Rahman, A.H.B.; Babikir, I.; Imran, Q.S.; Appiah, N.F.; Adeleke, T.O. Application of seismic attributes to delineate the geological features of the Malay Basin. Bull. Geol. Soc. Malays. 2020, 69, 97-110. [CrossRef]

17. Latiff, A.H.A.; Khalil, A.E. Crustal thickness and velocity structure of southern Peninsular Malaysia. Bull. Geol. Soc. Malays. 2018, 66, 7-13. [CrossRef]

18. Al-Masgari, A.A.-S.; Elsaadany, M.; Siddiqui, N.A.; Latiff, A.H.A.; Bakar, A.A.; Elkurdy, S.; Hermana, M.; Babikir, I.; Imran, Q.S.; Adeleke, T. Geomorphological Geometries and High-Resolution Seismic Sequence Stratigraphy of Malay Basin's Fluvial Succession. Appl. Sci. 2021, 11, 5156. [CrossRef]

19. Usman, M.; Siddiqui, N.A.; Garzanti, E.; Jamil, M.; Imran, Q.S.; Ahmed, L. 3-D Seismic-based Upper Jurassic to Lower Cretaceous stratigraphic and structural interpretation of the Gullfaks Field, Norwegian North Sea: A case study of reservoir development. Energy Geosci. 2021. [CrossRef] 
20. Jamil, M.; Siddiqui, N.A.; Rahman, A.H.B.A.; Ibrahim, N.A.; Ismail, M.S.B.; Ahmed, N.; Usman, M.; Gul, Z.; Imran, Q.S. Facies Heterogeneity and Lobe Facies Multiscale Analysis of Deep-Marine Sand-Shale Complexity in the West Crocker Formation of Sabah Basin, NW Borneo. Appl. Sci. 2021, 11, 5513. [CrossRef]

21. Imran, Q.S.; Siddiqui, N.A.; Latif, A.H.A.; Bashir, Y.; Ali, A.A.A.S.; Jamil, M. Integrated well data and 3D seismic inversion study for reservoir delineation and description. Bull. Geol. Soc. Malays. 2020, 70, 209-220. [CrossRef]

22. Jamil, M.; Siddiqui, N.A.; Umar, M.; Usman, M.; Ahmed, N.; Rahman, A.H.A.; Zaidi, F.K. Aseismic and seismic impact on development of soft-sediment deformation structures in deep-marine sand-shaly Crocker Fan in Sabah, NW Borneo. J. King Saud Univ. Sci. 2021, 101522. [CrossRef]

23. Madon, M. The Petroleum Geology and Resources of Malaysia; PETRONAS Carigali Sdn. Bhd.: Kuala Lumpur, Malaysia, 1999.

24. Ngah, K.; Madon, M.; Tjia, H. Role of pre-Tertiary fractures in formation and development of the Malay and Penyu basins. Geol. Soc. Lond. Spec. Publ. 1996, 106, 281-289. [CrossRef]

25. De Groot, P.; Ligtenberg, H.; Meldahl, P.; Heggland, R. Selecting and combining attributes to enhance detection of seismic objects. In 63rd EAGE Conference \& Exhibition; European Association of Geoscientists \& Engineers: Houten, The Netherlands, 2001; p. cp-15-00019.

26. Van Hoek, T.; Gesbert, S.; Pickens, J. Geometric attributes for seismic stratigraphic interpretation. Lead. Edge 2010, 29, 1056-1065. [CrossRef]

27. Marfurt, K.J.; Scheet, R.M.; Sharp, J.A.; Harper, M.G. Suppression of the acquisition footprint for seismic sequence attribute mapping. Geophysics 1998, 63, 1024-1035. [CrossRef]

28. Al-Bannagi, M.S.; Fang, K.; Kelamis, P.G.; Douglass, G.S. Acquisition footprint suppression via the truncated SVD technique: Case studies from Saudi Arabia. Lead. Edge 2005, 24, 832-834. [CrossRef]

29. Guo, H.; Marfurt, K.J.; Liu, J. Principal component spectral analysis. Geophysics 2009, 74, P35-P43. [CrossRef]

30. Davogustto, O.; Suarez, Y.; Marfurt, K.J. Footprint removal using adaptive subtraction algorithms for seismic attribute quality enhancement: A case study of Anadarko Basin Red Fork incised valley system. In SEG Technical Program Expanded Abstracts 2009; Society of Exploration Geophysicists: Tulsa, OK, USA, 2009; pp. 3390-3394.

31. Donias, M.; David, C.; Berthoumieu, Y.; Lavialle, O.; Guillon, S.; Keskes, N. New fault attribute based on robust directional scheme. Geophysics 2007, 72, P39-P46. [CrossRef]

32. Admasu, F.; Toennies, K. Automatic method for correlating horizons across faults in $3 \mathrm{~d}$ seismic data. In Proceedings of the 2004 IEEE Computer Society Conference on Computer Vision and Pattern Recognition, 2004. CVPR 2004, Washington, DC, USA, 27 June-2 July 2004; pp. I-I.

33. Bashir, Y.; Faisal, M.A.; Biswas, A.; abbas Babasafari, A.; Ali, S.H.; Imran, Q.S.; Siddiqui, N.A.; Ehsan, M. Seismic expression of miocene carbonate platform and reservoir characterization through geophysical approach: Application in central Luconia, offshore Malaysia. J. Pet. Explor. Prod. 2021, 11, 1533-1544.

34. Al-Masgari, A.A.-S.; Elsaadany, M.; Abdul Latiff, A.H.; Hermana, M.; Hamzah, U.B.; Babikir, I.; Adeleke, T.; Sohail Imran, Q.; Al-Bared, M.A.M. Seismic sequence stratigraphic sub-division using well logs and seismic data of Taranaki Basin, New Zealand. Appl. Sci. 2021, 11, 1226. [CrossRef]

35. Randen, T.; Pedersen, S.I.; Sønneland, L. Automatic extraction of fault surfaces from three-dimensional seismic data. In SEG Technical Program Expanded Abstracts 2001; Society of Exploration Geophysicists: Tulsa, OK, USA, 2001; pp. 551-554.

36. Aqrawi, A.A.; Boe, T.H. Improved fault segmentation using a dip guided and modified 3D Sobel filter. In SEG Technical Program Expanded Abstracts 2011; Society of Exploration Geophysicists: Tulsa, OK, USA, 2011; pp. 999-1003.

37. Hale, D. Fault surfaces and fault throws from 3D seismic images. In SEG Technical Program Expanded Abstracts 2012; Society of Exploration Geophysicists: Tulsa, OK, USA, 2012; pp. 1-6.

38. Hamidi, R.; Bashir, Y.; Ghosh, D.P.; Akhtar, S.; Sheikh, M.I. Application of Multi Attributes for Feasibility Study of Fractures and Structural Anomalies in Malaysian Basin. Int. J. Eng. Technol. 2018, 7, 84-87. [CrossRef]

39. Philit, S.; Pauget, F.; Lacaze, S.; Guion, C. To Boldly Go Where No Interpreter Has Gone Before. GEO ExPro Mag. 2019, 016, 56-58.

40. Fehmers, G.C.; Höcker, C.F. Fast structural interpretation with structure-oriented filtering. Geophysics 2003, 68, 1286-1293. [CrossRef]

41. Siddiqui, N.A.; Mathew, M.J.; Menier, D.; Hassaan, M. 2D and 3D seismic simulation for fault modeling: Exploratory revision from the Gullfaks field. J. Pet. Explor. Prod. Technol. 2017, 7, 417-432. [CrossRef] 